\title{
'Climate of fear' in new graduates: the perfect storm?
}

\author{
Kathryn Fox ${ }^{1}$
}

\section{Key points}

Highlights the societal features that may have influenced the clinical confidence of the current generation of dental graduates.
Identifies possible contributory factors to the current 'climate of fear'.
Discusses the role of the dental profession in facilitating the professional development of both dental students and recently qualified dental graduates.

\begin{abstract}
Today's dental graduates are entering the profession in a difficult environment, where patient complaints, litigation and referrals to the regulator are commonplace. This has been cited as causing a 'climate of fear'. However, in order to understand the pressures facing our new graduates, we must first understand how recent changes in society have affected the way in which this generation has been raised. We should also accept the role of individuals, and the profession as a whole, in changing the current climate and promoting graduates' professional development through appropriate risk management, coaching and mentoring.
\end{abstract}

\section{Introduction}

At the recent General Dental Council (GDC) conference launching the Moving upstream report, ${ }^{1}$ it was stated that dental students and newly qualified dentists were commencing their career in a 'climate of fear' due to patient complaints, litigation and the threat of the regulator. ${ }^{2}$ Although these factors undoubtedly increase the anxiety levels of newly qualified practitioners, the effect of changes in society during the past 25 years must also be considered. Current dental students and newly qualified dentists are known as 'Generation Z' or 'iGen' (born around 1995 onwards) and have grown up in a very different environment to those of previous generations, in terms of familial and societal upbringing, education and expectations. ${ }^{3}$ Most of these young adults have been raised by 'Baby Boomer' or 'Generation X' parents, whose own childhood consisted of hours of unsupervised outdoor play, freedom to meet with friends, no demands of social

'Senior Clinical Lecturer, School of Dentistry, University of Liverpool, Pembroke Place, Liverpool, UK.

Correspondence to: Kathryn Fox

Email: kfox@liverpool.ac.uk

Accepted 24 May 2019

https://doi.org10.1038/s41415-019-0673-0 media, and limited academic and external pressures regarding higher education.

Many of today's recent graduates, particularly those from middle-class families, have grown up as children in a culture of 'safetyism': ${ }^{4}$ car seat belts, bicycle helmets,

school security fences, school monitoring systems and tracking of their movements by their parents via smartphones. ${ }^{5}$ Schools have banned snowball fights, restricted adventurous play and focused on child safety at all times, for fear of injury and resultant litigation. This has predominantly been about physical safety, but more recently, it has also has moved to include emotional safety, with trigger warnings appearing before certain media reports and the introduction of no-platforming and 'safe place' policies by university student unions in order to ensure the security of vulnerable groups. ${ }^{4}$

In criticising young adults' behaviour, it is often convenient to ignore the role played by parents and society. In order to understand this further, the concept of social amplification of risk should be investigated. ${ }^{6}$ The technical concept of risk is determined by multiplying the probability of the event and the magnitude of the specific consequence. Therefore, society as a whole should be equally indifferent to high probability/low consequence events, as well as low probability/high consequence events. However, the perceived risk by individuals can be very different to the actual technical risk, due to the societal and cultural influences via public agencies, news and social media, and through personal experiences. This can lead to either an amplification or attenuation of the technical risk.

An example of amplification of risk is the heightened parental anxiety regarding child safety due to the increased awareness of child abductions (for example, 'Sarah's Law'). ${ }^{7}$ Consequently, many parents have felt compelled to supervise their children at all times, and as such have prevented the children developing their own independence whereas the incidence of child abduction in England and Wales decreased between 2004/05 and $2013 / 14,{ }^{8}$ so the technical risk had reduced. Although society encourages parents to make their children walk to school for the health benefits, the Irish Road Safety Authority advised that children under 12 years old should not be allowed to cross roads on their own. ${ }^{9}$ In England, the percentage of schoolchildren who travelled to school unaccompanied dropped from around $85 \%$ of 9-year-olds in 1971, to around $25 \%$ in $1990 .^{10}$ The NSPCC recommendations now state that children under 12 are rarely mature enough to be left alone at home for long periods, ${ }^{11}$ and in 2004 a father in the UK was prosecuted, and his children placed on the child protection 
register, for leaving his small child asleep in a car outside a chemist (while he was inside buying medicine for the child). ${ }^{12}$ This has resulted in parents being fearful not only of the dangers to their children from abduction, but also of prosecution. The consequence of this multimedia societal focus on the perceived risk of danger, and the subsequent overprotection of children, is a generation of young people who have been denied the opportunities to learn to take risks, manage failure and cope in difficult situations. Instead, they have received a consistent message from the adult population that life is dangerous and that adults will do everything in their power to protect them from harm's way. This well-meaning behaviour has inadvertently increased the anxiety levels of young people and prevented them from developing the capabilities and resilience required to become fully independent. ${ }^{13}$ It should not be a surprise, therefore, that this has also affected young dental graduates. The changes in preparedness for the adult working world have been prevalent throughout the lives of our recent graduates with the following factors playing a part.

\section{Education and play}

Psychologists have regularly reported that children inherently learn though play and have stressed the importance of free, undirected play with other children, as this is where children learn to cooperate, problem solve and regulate emotions. ${ }^{14}$ Children deprived of such play have been shown to be less able to take risks and be more prone to anxiety ${ }^{15}$ However, in developed nations, the opportunities for such play have steadily declined over the past 20 years, often substituted by online gaming which allows the parents to keep them safe at home or by a host of organised afterschool activities, aimed to enhance their children's personal statements for future university applications. This focus in society on 'safetyism' and academic achievements above all else has intensified the pressure on children to perform at levels that were never expected of their parents. It has also resulted in far fewer teenagers having part-time jobs or undertaking chores, both activities which are considered important in developing capabilities required for the transition to adulthood. ${ }^{13}$

In addition to the restricted development of independence due to societal concerns of safety, career-orientated parents of Generation X (early 1960s to mid-1980s), who have benefited from a higher education, unsurprisingly seek the same benefits for their offspring and as such have repeatedly stressed the importance to their children of getting into the 'right university' to study the 'right course'. As recently reported in the press, parents in the USA, unbeknown to their children, have even gone to illegal methods of ensuring a place in an Ivy League university. However, at what cost to the students, who have been sent the message yet again that they are incapable of achieving without their parents' intervention? This replacement of internal by an external locus of control, leads young people to feel like victims of circumstance and unable to deal with uncertainty or disputes. This has also led to some young people, particularly boys, to completely devolve responsibility for their futures to their parents, and as such have no internal motivation to succeed. ${ }^{16}$ The unfortunate consequence of this is that rather than developing the open-mindedness and psychological flexibility that students need to thrive at university and beyond, the rates of childhood and adolescent anxiety, depression and self-harm have steadily risen over the same period.

\section{Social media}

The rise of social media and the effect on mental health has been much debated. There has been a significant change in the way this generation communicate and a tendency to undertake far fewer face-to-face social interactions. This can lead to teenagers spending more time alone and missing out on the opportunities to develop discourse, conflict resolution skills, and to experience the real-world personal impact of ill thought-out comments, all of which are essential in the practise of dentistry. In addition, girls especially are subject to the adverse effect of comparing themselves to the enhanced selfies of celebrities or the psychological trauma of being intentionally left out. A consequence of this, is that teenagers who, by the nature of being indoors at home, are physically safer but emotionally and mentally more vulnerable. Many students currently arriving at university have often experienced less unsupervised time and fewer offline activities than any previous generation. As a result, they are often not fully prepared for independent life and unsurprisingly rely more heavily on parents or other adults for problem solving and conflict resolution than ever before. ${ }^{4}$

\section{Higher education}

Julie Lythcott-Haims, who was Dean of Freshmen at Stanford University, noticed changes in the behaviour of students attending from the year 2000, which, following the introduction of smartphones, gradually intensified over the following five to ten years. She noticed that the students were struggling to thrive independently from their parents and exhibited increasing levels of stress and anxiety. This led her to investigate the likely causes and resulted in her description of the overprotective effect of the 'helicopter parent. ${ }^{\text {'3 }}$

This observation has been mirrored in the UK where, due to the competitive nature of securing a place in dental school, the majority of students currently accepted are 'straight A' candidates, who may never have had to deal with any real failure; uncompleted homework has been finished by parents, gym kits forgotten have been brought to school to avoid detentions and any slightly suboptimal performance has been rectified with personal tutoring. There is a tendency, therefore, for students to rely on their parents to rescue them from any difficult situation. The emphasis, by both school and parents, on academic success has led students to take failure as a personal slight, rather than useful, although sometimes painful, feedback to be used constructively. This had led to many students lacking in self-efficacy (belief in their own capability) and resilience to the challenges, both academic and social, that arise at university. Consequently, many young adults are reluctant to take risks or step outside their comfort zones for fear of failure.

During induction at dental school, students are provided with the GDC document 'Student professionalism and fitness to practise.' ${ }^{17}$ This sets out the behaviours and attitudes expected of a dental professional, however it might be perceived as over-regulation by the student and as such increases the embedded notion of danger, raises anxiety levels and results in cautious rather than appropriate practises. The anxiety of GDC regulation, together with the consequences of the ubiquitous smartphone camera, is something previous generations did not even consider and, reflecting on their own student days, may be relieved that they did not have to. Poor attendance or the fraudulent act of signing a friend into a lecture could now lead to a student fitness to practise hearing, which if proven could stay on their record and will have to be declared when applying to join the dental register and for all future job applications. 
This cautious behaviour of students is also unintentionally reinforced during NHS training, as any near miss or adverse incident is recorded on the NHS 'Datix' system. This is a non-judgemental system of improving patient safety, where lessons can be learned and adverse events avoided. However, undergraduates ensconced in a culture of safety and a fear of failure can often respond to such an event in a defensive manner, and this may result in significant anxiety rather than a constructive learning experience. Accepting and learning from feedback is an important characteristic of a dental professional, but one which takes time to develop. A study of UK university students has shown that having been previously educated in a system that is predominantly results- and grades-focused, students often feel that the 'mark' or 'grade' achieved is all that counts, and consequently are often reluctant to take on board any further feedback..$^{18}$ In addition, due to pressures from both parents and school league tables, the recent culture in high schools and sixth form colleges is to challenge the GCSE and A-level grades with the exam boards. Therefore, the trainees' natural instincts are often to challenge the feedback given rather than use it for their own development. This has encouraged a tendency towards a 'fixed' rather than a 'growth mindset'; the student thereby loses learning opportunities for the future and also increases their avoidance behaviours. ${ }^{19}$ A situation that may also explain why some graduates seem to dramatically underreport dental school experience to foundation trainers, as a mechanism to avoid being asked to do something that they fear they could get wrong.

In 2009, the National Patient Safety Agency introduced the list of 'Never Events' which has been updated in $2018 .{ }^{20}$ If such an event occurs, the senior management team of the hospital trust is informed and subsequently a full investigation takes place. As the Never Events list included both block anaesthesia (recently removed) and permanent tooth extraction, this led to some dental tutors no longer being prepared to allow dental students to undertake ID blocks or extractions independently, for the fear of wrong site surgery taking place. This has heightened the anxiety levels of both staff and students, and may have contributed to increased levels of fear in graduates undertaking extractions in dental foundation training.

The GDC states that their message is clear: 'no dental professional who understands their obligations to patients and the public, and takes them seriously, should have anything to fear from the regulation. ${ }^{1}$ However, all practising dentists now have anecdotes of colleagues who have been referred to the GDC, and the resulting high levels of anxiety that this incurs, whether or not there is ultimately a case to answer. Dental students are also aware of such cases, which in the past would have been a rarity, and therefore are often discussed in undergraduate law and ethics teaching. Dental students are now experiencing, at close-hand, dental surgeons who they respect going through this process. This can unfortunately reinforce their belief that they must not make mistakes. In addition, the persistent advertising of medical negligence companies increases the feeling of fear and danger which has been initiated by the 'safetyism' of their childhood. This climate of fear leads to avoidance behaviour and defensive practice, which in the long-run is to the detriment of the patients, and leads to deskilling of the dentist.

\section{Changing the climate}

Those of us who are parents (including the author) need to allow young people the freedom to learn to take and manage risks, accept the consequences of their own decisions and be allowed to fail. ${ }^{13}$ Children need to be given the time and space to take part in free-play with their friends and should be encouraged to take on challenges to develop belief in their own capabilities and resultant self-efficacy. We also need to keep in check our levels of perceived risks versus actual risks and dangers, and allow children the freedom to develop their own ideas and learn from their mistakes. Doing less, rather than more, for our children signals our confidence in them and develops their self-efficacy, and then they are more willing to take on further challenges.

Fortunately, some primary and high schools in the UK have become aware of the students' tendencies towards this maladaptive behaviour, and are introducing mindfulness and resilience training to the curriculum in an attempt to build psychological toughness and decrease the anxiety felt by these children. The culture of overprotection became embedded into society in the USA before the UK, and an organisation called 'LetGrow' is now attempting to counter this trend. This is being done by engaging parents, schools and communities to facilitate ways in which children can develop more independence and resilience, and highlighting how treating children as physically and emotionally fragile is detrimental to their development into adulthood. ${ }^{21}$

University educators need to aid the transition of emerging adults into full adulthood and support them in areas such as dealing with uncertainty, learning to cope with failure, assessment of risk, self-reflection and goal setting. Educators in dental schools and foundation training also have a role in delivering constructive feedback by tailoring it to the specific task that is being undertaken, in order to encourage the trainee to reflect and identify areas for their development. A coaching approach rather than a judgemental one is required. The judgemental approach tends to encourage the defensive, grade-orientated response in the trainee who may respond personally, whereas a coaching approach allows the trainee to reflect on their experience and identify their areas for development and take feedback as to how these can be addressed. In addition, the importance of self regulation ${ }^{22}$ (controlling one's behaviours, emotions and thoughts in pursuit of long-term goals), has been highlighted to dental students as mechanisms ${ }^{23}$ (to help deal with such emotions) have been introduced in some schools. In addition, sessions regarding personal values, accepting feedback, the effect of mindset and the benefits of personal goal setting have been found to be of benefit to students. The aim of these interventions is to facilitate students who have grown up in a culture of 'safetyism' to deal with uncertainty, develop their risk-taking abilities, improve resilience and to cope with failure or adverse outcomes. This needs to be consolidated in foundation training in order to develop the trainees' confidence in their own ability to take on challenging situations.

Although society has become far more litigious over the past ten years, dental indemnity organisations (DIOs) have a role to play in educating dental students and young dentists on the technical rather than perceived risks of patient litigation and referral to the regulator, and how these can best be dealt with throughout a dentist's career, without causing undue stress and anxiety. In addition, DIOs could play an important role in continuing professional development on subjects such as dealing with difficult interactions, conflict resolution and managing patient complaints, to prevent these from escalating. The profession should also campaign against the ubiquitous advertising of ambulance-chasing law firms and 'no-win, no-fee' contracts, which ultimately lead to defensive practice and poorer patient outcomes. 
The future profession would benefit from the General Dental Council actively engaging with the dental schools (there have recently been some sessions where the GDC has met with first year dental students), about their role and regarding fitness to practise processes (both as a student and a registrant), so that the students fully understand the purpose of the GDC and how its processes are implemented. This, together with a reduction in formal investigations, may help to dissipate the fear of the regulator in the long-term and any resultant avoidance behaviours. In order for the GDC to regain the trust of the profession, it is essential that, as stated by Eddie Crouch at the Moving upstream launch:

'The GDC now seems to recognise that sometimes professionals make mistakes and that anyone who takes that seriously should have nothing to fear from the regulator. These are fine words and we now need actions to back that $u p^{\prime 2}{ }^{2}$ It is therefore unfortunate that the headline overleaf from the $B D J$ Upfront article stated: 'Fitness to practise cases predicted to rise slightly in 2019'!

\section{Conclusion}

Dental students and newly qualified graduates will mirror the response of their senior colleagues, so until dentists are comfortable owning up to their mistakes and doing the right thing without fear of prosecution, the next generation will continue to struggle further in this climate of fear, rather than developing the resilience and clinical confidence required to become the competent clinicians that our patients require.

Acknowledgements

The author would like to thank Dr Alex Forsythe and Prof Luke Dawson for their helpful feedback in the preparation of this publication.

\section{References}

1. General Dental Council. Moving upstream. 2019. Available at https://www.gdc-uk.org/about/what-we-do/ shifting-the-balance/moving-upstream (accessed August 2019).

2. O'Dowd A. Regulator seeks to tackle 'climate of fear' among new dentists. Br Dent J 2019: 226: 247.

3. Twenge J M. iGen: Why today's super-connected kids are growing up less rebellious, more tolerant, less happy - and completely unprepared for adulthood - and what that means for the rest of us. New York: Atria Books, 2017.

4. Lukianoff $\mathrm{G}$, Haidt J. The coddling of the American mind: how good intentions and bad ideas are setting up a generation for failure. London: Penguin Press, 2018.

5. Anderson M. Parents, teens and digital monitoring. 2016. Available at http://www.pewinternet. org/2016/01/07/parents-teens-and-digital-monitoring (accessed August 2019).

6. Kasperson R E, Renn O, Slovic P et al. The social amplification of risk: a conceptual framework. Risk Anal 1988; 8: 177-187.

7. BBC News. 'Sarah's Law' scheme covers all England and Wales. 2011. Available at https://www.bbc.co.uk/news/ uk-12952334 (accessed August 2019).

8. Child Abduction UK. Available at http://www. childabduction.org.uk/index.php/child-abduction (accessed August 2019).

9. Road Safety Authority. Going to school: a parents guide to getting children to school safely. 2017. Available at https://www.rsa.ie/Documents/Road\%20Safety/ Leaflets/Leaf_booklets/Going_to_school.pdf (accessed August 2019).

10. Shaw B, Watson B, Frauendienst B, Redecker A, Jones T, Hillman M. Children's independent mobility: a comparative study in England and Germany (1971-2010). 2012. Available at http://www.psi.org.uk/ images/uploads/CIM_Final_report_v9_3_FINAL.PDF (accessed August 2019).

11. UK Government. The law on leaving your child on their own. Available at http://www.gov.uk/law-on-leavingyour-child-home-alone (accessed August 2019).

12. Fifield N. Father prosecuted after leaving daughter in car for ten minutes. The Telegraph (London) 2014 November 23. Available at https://www.telegraph.co.uk/news/ uknews/law-and-order/11249091/Father-prosecutedafter-leaving-daughter-in-car-for-ten-minutes.html (accessed August 2019).

13. Lythcott-Haims J. How to raise an adult. London: Bluebird, 2015.

14. Gray P. The decline of play and the rise of psychopathology in children and adolescents. Am J Play 2011; 3: 443-463.

15. O'Brien J, Smith J. Childhood transformed? Risk perception and the decline of free play. Br J Occup Ther 2002; 65: 123-128.

16. Price A. He's not lazy: empowering your son to believe in himself. New York: Sterling, 2017.

17. General Dental Council. Student professionalism and fitness to practise. 2016. Available at https://www. gdc-uk.org/api/files/full\%20guidance $\% 20$ for $\% 20$ students.pdf (accessed August 2019).

18. Forsythe A, Johnson S. Thanks, but no-thanks for the feedback. Assessment \& Evaluation in Higher Education 2017: 42: 850-859.

19. Dweck C. Mindset: changing the way you think to fulfil your potential. London: Robinson, 2017.

20. NHS Improvement. Never Events list 2018. Available at https://improvement.nhs.uk/documents/2266/ Never_Events_list_2018_FINAL_v5.pdf (accessed August 2019).

21. Let Grow. Available at https://letgrow.org (accessed August 2019).

22. Bandura A. Social cognitive theory of self-regulation. Organ Behav Hum Decis Process 1991; 50: 248-287.

23. Parkinson B, Totterdell P. Classifying Affect-regulation strategies. Cogn Emot 1999; 13: 271-303. 